\title{
Sacral Plexus
}

National Cancer Institute

\section{Source}

National Cancer Institute. Sacral Plexus. NCI Thesaurus. Code C12846.

A network of nerve fibers that are derived from the anterior rami of spinal nerves L4-L5 and S1-S4, and which are part of the larger lumbosacral plexus, providing motor and sensory innervation for the posterior thigh, most of the lower leg, the entire foot, and part of the pelvis. 